\title{
nal Burøau of Standards
}

Jilorary, N.V. BIdB

UUL $3 \quad 1963$

NBS

Eechnical Note

\section{PHOTOTYPESETTING OF COMPUTER OUTPUT}

AN EXAMPLE USING TABULAR DATA

WILLIAM R. BOZMAN

U. S. DEPARTMENT OF COMMERCE NATIONAL BUREAU OF STANDARDS 


\section{THE NATIONAL BUREAU OF STANDARDS}

\section{Functions and Activities}

The functions of the National Bureau of Standards are set forth in the Act of Congress, March 3, 1901, as amended by Congress in Public Law 619, 1950. These include the development and maintenance of the national standards of measurement and the provision of means and methods for making measurements consistent with these standards; the determination of physical constants and properties of materials; the development of methods and instruments for testing materials, devices, and structures; advisory services to government agencies on scientific and technical problems; invention and development of devices to serve special needs of the Government; and the development of standard practices, codes, and specifications. The work includes basic and applied research, development, engineering, instrumentation, testing, evaluation, calibration services, and various consultation and information services. Research projects are also performed for other government agencies when the work relates to and supplements the basic program of the Bureau or when the Bureau's unique competence is required. The scope of activities is suggested by the listing of divisions and sections on the inside of the back cover.

\section{Publications}

The results of the Bureau's research are published either in the Bureau's own series of publications or in the journals of professional and scientific societies. The Bureau publishes three periodicals available from the Government Printing Office: The Journal of Research, published in four separate sections, presents complete scientific and technical papers; the Technical News Bulletin presents summary and preliminary reports on work in progress; and the Central Radio Propagation Laboratory Ionospheric Predictions provides data for determining the best frequencies to use for radio communications throughout the world. There are also five series of nonperiodical publications: Monographs, Applied Mathematics Series, Handbooks, Miscellaneous Publications, and Technical Notes.

A complete listing of the Bureau's publications can be found in National Bureau of Standards Circular 460, Publications of the National Bureau of Standards, 1901 to June 1947 (\$1.25), and the Supplement to National Bureau of Standards Circular 460, July 1947 to June 1957 (\$1.50), and Miscellaneous Publication 240, July 1957 to June 1960 (includes Titles of Prpers Published in Outside Journals 1950 to 1959) (\$2.25); available from the Superintendent of Documents, Government Printing Office, Washington 25, D.C. 


\title{
NATIONAL BUREAU OF STANDARDS
}

\author{
Eechnical Note 170
}

ISSUED JUNE 25, 1963

\section{PHOTOTYPESETTING OF COMPUTER OUTPUT \\ AN EXAMPLE USING TABULAR DATA}

William R. Bozman

NBS Technical Notes are designed to supplement the Bureau's regular publications program. They provide a means for making available scientific data that are of transient or limited interest. Technical Notes may be listed or referred to in the open literature. 


\section{Contents}

1. Photocomposition of computer output................................. 1

2. Description of character codes........................................ 1

3. Conclusion......................................................... 4 


\title{
Phototypesetting of Computer Output
}

\author{
William R. Bozman
}

\begin{abstract}
A photocomposition machine controlled by the magnetic tape output from a computer was used to prepare a 559-page table of atomic transition probabilities at the National Bureau of Standards. This method makes possible the publication of computed data in high quality typography in a reasonable time and at a reasonable cost. Many styles of type are readily available to the programmer including Greek, italic, mathematical symbols, upper and lower case alphabets, etc.
\end{abstract}

\section{Photocomposition of Computer Output}

Modern electronic computers are used to calculate and process large quantities of basic mathematical and physical data. Hundreds of pages of numerical or tabular information can be obtained in a few hours, or even a few minutes. When the final calculations are completed, the problem of publication of the data then arises.

This problem can be handled in two ways. Traditionally the information is set in metal type. This method produces high quality typography of graphic art quality, and is the preferred style. However, in order to minimize the time needed between the computer calculations and the final printed page, and also to reduce printing costs, it is frequently decided to forgo traditional typographic quality. In these instances the printing plates may be made from photographs of pages prepared on a high-speed computer printer.

Unfortunately these printed pages are usually much less clear than those that have been typeset, page formats may be wasteful of space, and the limitations on the styles of type and special characters available may be a severe handicap, leading to the use of nonstandard or even misleading notations.

A solution to this dilemma is now possible by using an automated photocomposition machine which can produce first class typography in a reasonable time and at a reasonable cost.

A recent publication of the National Bureau of Standards produced by this method is NBS Monograph 53, Experimental Transition Probabilities for Spectral Lines of Seventy Elements by C. H. Corliss and W. R. Bozman.

The transition probabilities were computed by an IBM 7090 electronic computer and written onto a magnetic tape in a Binary-Coded-Decimal (BCD) form. This BCD tape was printed on the IBM 1403 printer for reference purposes. A FORTRAN computer code was then written to convert this BCD tape into a binary tape which contained the proper bit-patterns to operate a magnetic-tape-controlled Linofilm photocomposition machine. This machine was located at the IBM Watson Research Center where it was being used in a language translation project.

The table of transition probabilities consists of 559 pages of data. Preparation of the film from the magnetic tape took about 80 hours. About twelve 50 -foot rolls of 8-inch wide positive film were used. The plates for offset printing were made photographically, directly from the films. The computation of the data and preparation of the BCD tape took twenty minutes on a 7090 computer; the conversion from the BCD tape to the binary tape in Linofilm format took thirteen minutes. It would have taken about 300 hours to set the table by conventional methods. The proofreading and correcting of typographical errors would also have taken considerably more time, especially since the table produced was not completely proofread. (After proofreading the first few pages without finding an error, a decision was made to check only the first and last line of each page.)

Data for a second publication, Spectral-Line Intensities and gf-Values in the First Spectrum of Copper by Charles H. Corliss, National Bureau of Standards Journal of Research 66A (Physics and Chemistry), No. 6, 497 (Nov.-Dec. 1962), was prepared by using a magnetic-tape-to-paper-tape converter. The paper tape was then fed into a standard (paper-tape-controlled) photocomposition machine.

\section{Description of Character Codes}

The binary magnetic tape for input to the paper tape converter was recorded in "records" of 250 computer "words" of 36 bits each at high density (556 bits per inch). Each computer word contained two characters to be typeset, corresponding to two rows of holes on the 15-channel paper tape.

The binary information on the magnetic tape must correspond exactly to the binary holes to be punched on the paper tape, except for three bits per character which are not read from the magnetic tape. These extraneous bits are taken care of automatically by the proper choice of octal numbers which represent each character. For example, if the upper case letter, capital " $A$ " is designated by the octal numbers $0504_{8}$ followed by the proper width information for the font to be used, e.g., a width of thirteen units $=15_{8}$ units, then the octal number $050415_{8}$ will write the proper bit pattern on the magnetic tape (eighteen bits) so that the correct fifteen-bit pattern will be punched on the paper tape. All letters, numbers and printed symbols start their code number with a zero. Instructions to the photocomposition machine such as "change grids," "change point 
size," "justify," or "quad left," etc., start with a 1, 2, or 3 as the first digit.

As each computer word (IBM7090) consists of 36 bits, it is possible to place two characters in each word. For example, the chemical symbol for sodium, $\mathrm{Na}$, would be written on the magnetic tape as 040416022311, the 0404 representing the upper case "N" having a width of $16_{8}$ units and the 0223 the lower case "a" having a width of $1 l_{8}$ units.

These computer words are prepared by a computer code. Our data were converted from a BCD magnetic tape, in standard IBM format, to the binary magnetic tape, in Linofilm format, by a FORTRAN code containing a SUBROUTINE (FORTRAN subroutine) of the following type:

\begin{tabular}{|c|c|c|c|}
\hline \multirow{2}{*}{ LINOB } & ENTRY & \multicolumn{2}{|l|}{ LINOB } \\
\hline & $\begin{array}{l}\text { SXA } \\
\text { SXA }\end{array}$ & $\begin{array}{l}\mathrm{XR} 1,1 \\
\mathrm{XR} 2,2\end{array}$ & \\
\hline \multirow{11}{*}{ LOOP } & AXT & & INPUT \\
\hline & AXT & & OUTPUT \\
\hline & LDQ & DATA $+1,1$ & \\
\hline & CAQ & TABLE-127,0,1 & FIRST CHARACTER \\
\hline & ALS & 18 & SFCOND CHAB ACTER \\
\hline & $\begin{array}{l}\text { CAQ } \\
\text { SLW }\end{array}$ & $\begin{array}{l}\text { 1 ABLE-12 }+1,0,1 \\
\text { OUTPUT }+1,2\end{array}$ & SELOND CHAKACIEK \\
\hline & $\begin{array}{l}\text { TXI } \\
\text { ZAC }\end{array}$ & ${ }^{*}+1,2,1$ & \\
\hline & CAQ & TABLE-127,0,1 & THIRD CHARACTER \\
\hline & ALS & 18 TABLE- 12701 & FOURTH CHARACTER \\
\hline & SLW & OUTPUT+1,2 & \\
\hline & $\begin{array}{l}\text { TXI } \\
\text { ZAC }\end{array}$ & $*+1,2,1$ & \\
\hline \multirow{6}{*}{ ALS18 } & $\mathrm{CAQ}$ & TABLE- $127,0,1$ & FIFTH CHARACTER \\
\hline & ALS & & \\
\hline & CAQ & TABLE- $127,0,1$ & SIXTH CHARACTER \\
\hline & SLW & OUTPUT $+1,2$ & \\
\hline & $\begin{array}{l}\text { TXI } \\
\text { TXI }\end{array}$ & $\begin{array}{l}*+1,2,1 \\
*+1,1,1\end{array}$ & \\
\hline & TXL & LOOP,1,12 & \\
\hline $\mathrm{XR} \mathbf{l}$ & $\mathrm{AXT}$ & $*, 1$ & \\
\hline \multirow[t]{2}{*}{$\mathrm{XR2}$} & AXT & $*, 2$ & \\
\hline & TRA & 1,4 & \\
\hline DATA & COMMON & 12 & \\
\hline OUTPUT & COMMON & & \\
\hline TABLE & COMMON & 2584 & \\
\hline PAGENC & COMMON & & \\
\hline PRNTNC & $\begin{array}{l}\text { COMMON } \\
\text { END }\end{array}$ & & \\
\hline
\end{tabular}

This subroutine selects the proper Linofilm codes from a table in the following way: A word (36 bits in BCD) of DATA is loaded by the LDQ instruction into the Multiplier Quotient Register (MQ). (For example, "HG 198" would be loaded as 30276001. 11108.) The Accumulator Register (AC) is cleared by the ZAC; then the CAQ instruction reads the first six bits of the DATA word in the MQ (the $30_{8}$ representing the " $\mathrm{H}$ " in the example) and adds this number to TABLE-127 to form a new address, TABLE-127+30. This location contains the Linofilm bit pattern for the letter "h."

In the actual SUBROUTINE used for Monograph 53, the first letter of each chemical symbol was capitalized. This was done by having two tables, TABLE-127 containing the lower case or unshifted characters and TABLE-63 containing the upper case or shift position characters. The proper table was selected by the code; in the above example the address actually chosen would have been TABLE- $63+30$, containing the Linofilm bit pattern for the upper case " $\mathrm{H}$ " $(033313$, the 333 representing the letter " $\mathrm{H}$ ", the 13 giving the width of the letter, and the left-most digit being zero since this is a character to be printed). This number is added into the AC which then contains 000000033313. The CAQ instruction rotates the DATA in the MQ six bits to the left so that the next character, represented by 27, is in the left six bits of the MQ. The contents of the $A C$ are then shifted left 18 binary places by the ALS 18 instruction, in order to make room for the second character. The AC now contains 033313000000.

The next computer instruction, which is another CAQ, looks up the 27th (octal) entry in TABLE-127, which would be the Linofilm bit-pattern for lower case " $g$ ", and adds it to the contents of the AC:

$$
\begin{aligned}
& 033313000000_{8}=\mathrm{H} \\
& 000000012310_{8}=\mathrm{g} \\
& 033313012310_{8}=\mathrm{Hg} .
\end{aligned}
$$

This value is stored in the OUTPUT. The code then continues with the "space" and the numeral 1 which would be stored in the OUTPUT as 0000060 $20511_{8}$. In this case the "space" is given a value of 6 units, but it could be any value desired from $04_{8}$ to $37_{8}$ units. The last two digits, 98 , would be stored as $021211022511_{8}$.

Note that all the numerals have a constant width, in this instance $11_{8}$. The width to be used is of course determined by the choice of type style. This SUBROUTINE will convert all BCD data into the proper bit patterns for the photocomposition machine. However, additional instructions are needed for the operation of the photocomposition machine. The first computer word on the output tape must contain the point size and film advance information as shown in the octal printout of figure 1. For example, if a 10 point type size with a 10 point film advance is specified, then the first word would be $240500221200_{8}$ in which 2405 designates "change point size" to the fifth size listed. "The next two zeros are ignored. The 2212 specifies the film advance to be $12_{8}$ units, which equals 10 points. The next instruction is the grid selection; in order to simplify the coding problem this instruction was repeated, so that the second word on the magnetic tape was 260400260400 to instruct the machine to choose grid number 04 . The right-hand half of this word could, of course, be the first character of the output information.

An "end-of-line" code must be given at the end of each line. This work, being tabular, was given a "Quad left" instruction. In order to simulate this instruction as punched on the standard paper tape, the following is written on the magnetic tape: $311400100000_{8}$ followed by six words of zeros, i.e.: 000000000000 written six times. 
Ten quad-lefts were written on the tape at the end of each page in order to give 10 blank lines between the pages for cutting them apart.

The output tape must be written in the binary mode and must not contain any extraneous words such as tape-checking words. This meant that the FORTRAN "WRITE TAPE" instruction cannot be used. However, a subroutine can be called by a FORTRAN statement such as:

\section{CALL WTBA6 (BLOCK(J),K,IOERR)}

where $J$, is the index for the end of each record, $K$, is the record size e.g. 250, and IOERR is the tape error

exit. The following SUBROUTINE written in the FAP symbolic coding system was used:

$\begin{array}{lll} & \text { ENTRY } & \text { WTBA6 } \\ \text { WTBA6 } & \text { SXA } & \text { XRA,1 } \\ & \text { AXT } & 10,1 \\ & \text { CLA } & 1,4 \\ & \text { STA } & \text { IO } \\ \text { CLA } & 2,4 \\ & \text { STD } & \text { IO } \\ \text { WTBA } & 6 \\ \text { RCHA } & \text { IO } \\ \text { TCOA } & * \\ \text { TEC } & *-1 \\ \text { TRCA } & *+5\end{array}$

000036000030 023407051406 042306051406 022415040311 000000000000 000000000000 04052202230 012310031511 000036000007 000000000000 00000605041 260100030606 000000000000 000000000000 023105032512 000012031212 052512000012 000012000012 000000000000 000012000012 021212053212 000012000012 053212053212 311400100000 042512041212 000012000012 041212021212 000012000012 012212052512 000000000000 04251204121
030414022312 042306051406 030310023407 032312042306 000000000000 000000000000 041511030311 000006053314 012310052307 000000000000 000036000036 023407030311 000000000000 000012000012 022512000012 021212053212 000012000012 000012000012 000000000000 052512032512 020512021212 053212023105 031212051212 000000000000 000012000012 000012000012 000012000012 000012000012 023105053212 000000000000 023105051212
020312021411 040311032312 00000604031 051405032312 000000000000 000000000000 02140603031 30311041511 000036000036 000000000000 000036000036 050311260300 311400100000 031212022512 000012000012 353212051212 000012000012 012212052512 000000000000 051212053212 000012012212 053212031212 000012000012 000000000000 000012000012 000012051212 000012000012 053212023105 021212000012 000012000012 053212000012
030312000006 000006060312 052307000006 053412030311 000000000000 023304032313 032313012310 030311021406 000022053314 000000000000 000027013317 311400100000 000000000030 000012000012 000012000012 000012000012 000012000012 023105051212 000000000000 023105053212 000012031212 053212000012 000012000012 000000000000 000012000012 021212053212 000012000012 053212053212 311400100000 042512020512 000012000012
053212020512 000012000012 053212053212 311400100000 032512053212 000012000012 042512020512 000012000012 012212052512 CCOCOC 000000 CCOCOCCOOOOS 023105042512 000012031212 022512031212 000012000012 $00 \mathrm{C0000C0000}$ $0 C 0012 \mathrm{COOO} 12$ 021212053212 000012000012 053212053212 311400100000 022512041212 000012000012 031212051212 000012000012 012212052512
$000012 C C 0012$ CCCO12042512

020512042512 053212023105 052512051212 000000000000 $000012 \mathrm{CCOO} 12$ 000012000012 000012000012 $\mathrm{CCCO12CCOO12}$ 023105042512 CCCCC 0000000 C00012000012 022512000012 032512053212 C000120C0012 000012000012 Ccoco0000000 052512022512 020512021212 053212023105 021212031212 cccccc000000 000012000012 C000120C0012 C00012000012 000012000012 023105022512
000000000000 000012000012

000012012212 053212052512 000012000012 000000000000 000012000012 000012042512 000012000012 053212023105 031212000012 311400100000 020512041212 000012000012 032512042512 000012000012 012212052512 000000000000 041212022512 000012012212 053212022512 000012000012 000000000000 000012000012 000012020512 $000012 C 00012$ 053212023105 021212000012

000000000000 052512032512

000012031212 052512000012 000012000012 000000000000 000012000012 053212020512 000012000012 053212053212 311400100000 000000000000 000012000012 000012000012 000012000012 000012000012 023105021212 000000000000 023105052512 000012031212 053212000012 000012000012 000000000000 000012000012 020512052512 000012000012 053212053212 311400100000
031212021212 000012000012 000012000012 000000000000 052512032512 020512042512 053212023105 051212042512 000000000000 000000000000 000012000012 000012042512 000012000012 05321202310 022512000012 000012020512 052512000012 051212021212 000012000012 000012000012 000000000000 052512022512 053212051212 053212023105 020512051212 000000000000 


$\begin{array}{lll}\text { XRA } & \text { AXT } & *, 1 \\ \text { OUT } & \text { TRA } & 4,4 \\ \text { ERR } & \text { STZ } & 3,4 \\ & \text { TRA } & 4,4 \\ & \text { TNX } & \text { ERR, } 1,1 \\ & \text { BSRA } & 6 \\ & \text { TRA } & \text { B } \\ \text { IO } & \text { IOCD } & * *, 1 \\ & \text { END } & \end{array}$

An example of the data on the binary tape is given by the octal print-out in figure 1 . The data of figure 1 may be interpreted by the use of the octal codes given in figures 2 and 3 . The final result, as produced by the photocomposition machine, is shown in figure 4.

\section{Conclusion}

Computed and computer-processed data can now be prepared for publication by an automatic method that retains the high typographic quality of conventional typesetting. Better page formats with less waste space result in less cost for paper, with the added benefit of a smaller size which is easier to handle. Probably the most important improvement, however, is in readability. The printing is not only clear and distinct, but the availability of a choice of type styles, mathematical symbols, special symbols, and Greek and italic characters to fit each particular job contributes toward the publication of data which is easier to understand and a pleasure to read and use.

Keyboord Chart
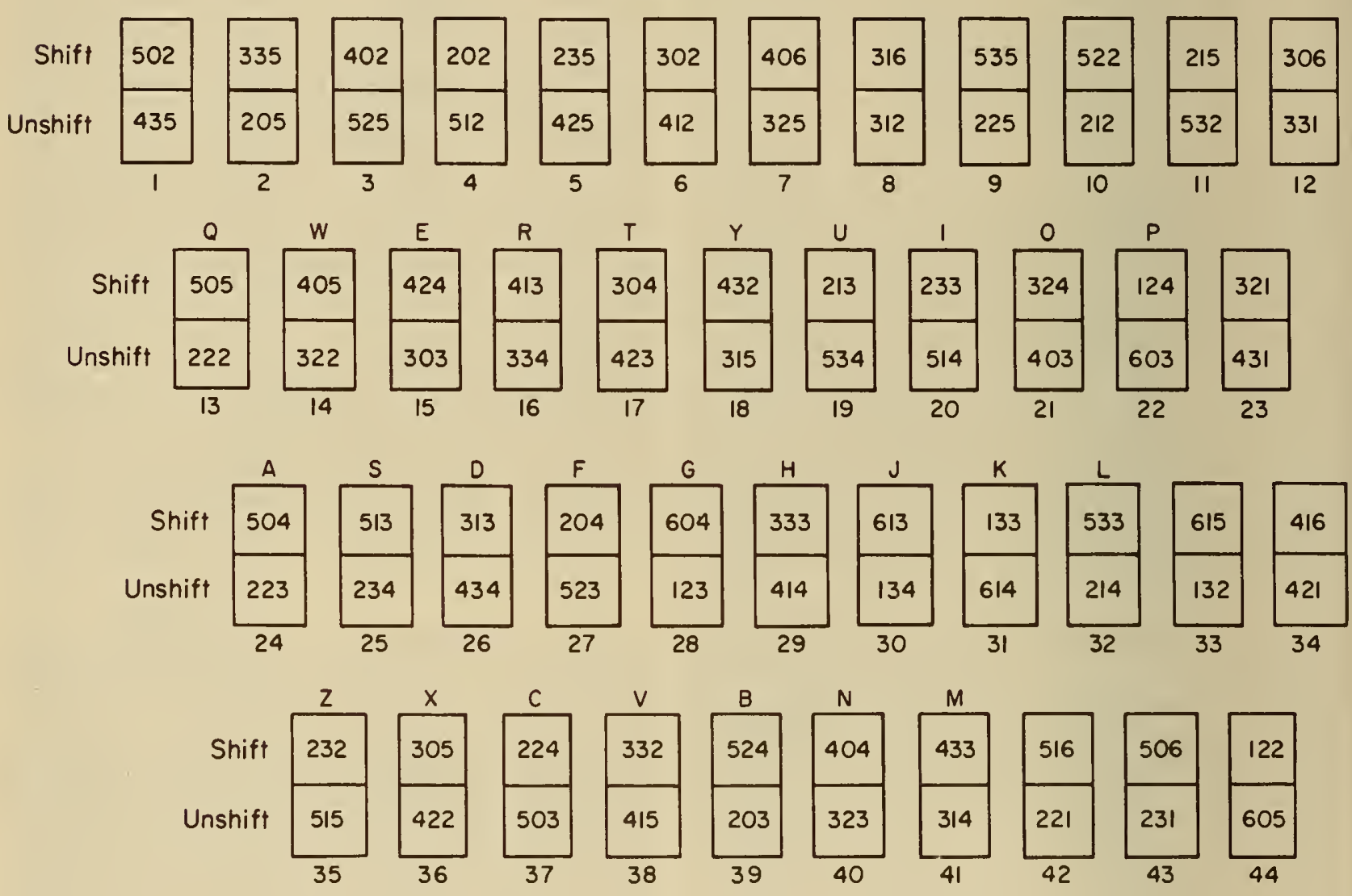

FIGURE 2. Keyboard chart showing the octal code for each key position.

\section{Acknowledgment}

I wish to thank all those who helped me with this problem, especially Charles DeWitt Coleman for his valuable suggestions and assistance with the computer programming. 


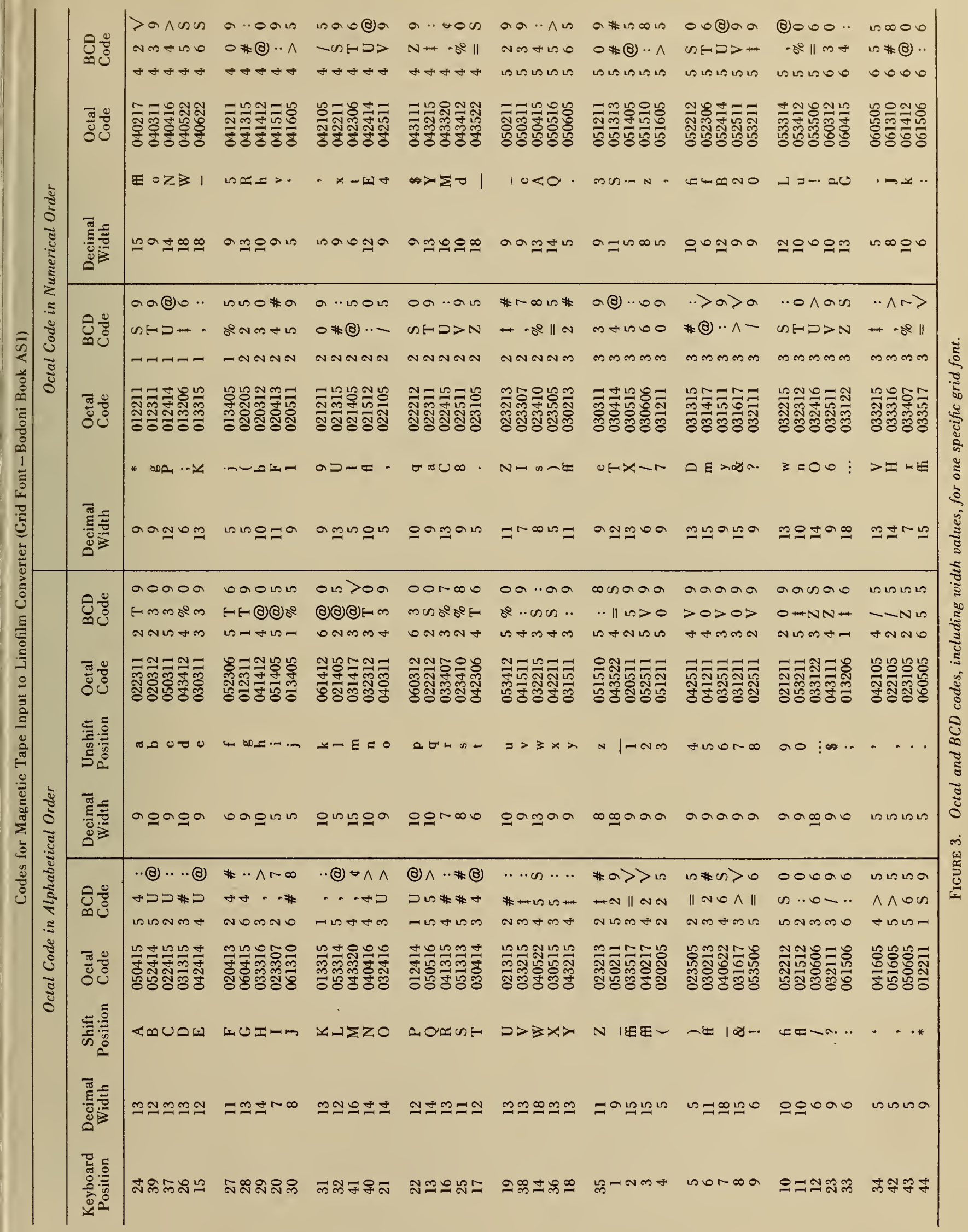


TABLE 1. Transition probabilities of copper-Continued

$\begin{array}{rcclll}\text { Intensity } & \begin{array}{c}\text { Wavelength } \\ \text { A }\end{array} & \begin{array}{c}\text { Energy Levels } \\ \text { K }\end{array} & \begin{array}{c}\text { gA } \\ 10^{8} / \mathbf{s e c}\end{array} & \text { gf } & \text { Log gf } \\ 78 & 2626.68 & 40944-79003 & 0.042 & 0.0043 & -2.36 \\ 131 & 2630.00 & 39019-77031 & 0.070 & 0.0073 & -2.14 \\ 145 & 2634.93 & 39019-76959 & 0.078 & 0.0081 & -2.09 \\ 41 & 2645.30 & 40114-77905 & 0.022 & 0.0023 & -2.63 \\ 60 & 2649.84 & 40114-77841 & 0.033 & 0.0034 & -2.47 \\ & & & & & -2.98 \\ 15 & 2846.48 & 40944-76064 & 0.0087 & 0.0011 & -2.01 \\ 139 & 2858.22 & 39019-73995 & 0.080 & 0.0097 & -2.89 \\ 185 & 2858.73 & 11203-46173 & 0.010 & 0.0013 & -2.32 \\ 65 & 2890.84 & 44406-78988 & 0.038 & 0.0048 & -2.38 \\ 56 & 2891.64 & 44544-79116 & 0.033 & 0.0042 & -3.08 \\ & & & & & -2.66 \\ 11 & 2931.70 & 40944-75044 & 0.0065 & 0.00084 & -2.02 \\ 29 & 2933.06 & 39019-73103 & 0.017 & 0.0022 & -2.08 \\ 119 & 2978.30 & 43514-77080 & 0.072 & 0.0096 & -3.32 \\ 103 & 2979.38 & 43514-77068 & 0.063 & 0.0083 & \\ 98 & 2998.38 & 11203-44544 & 0.0036 & 0.00048 & -1.88 \\ & & & & & -2.35 \\ 161 & 3012.00 & 40114-73305 & 0.096 & 0.013 & -1.80 \\ 54 & 3014.85 & 41153-74313 & 0.033 & 0.0045 & -1.84 \\ 191 & 3021.54 & 40909-73995 & 0.12 & 0.016 & -2.22 \\ 179 & 3022.61 & 39019-72093 & 0.11 & 0.015 & \end{array}$

FIGURE 4. Portion of page from the machine that was produced from the data illustrated in figure $I$. 


\section{THE NATIONAL BUREAU OF STANDARDS}

The scope of activities of the National Bureau of Standards at its major laboratories in Washington, D.C., and Boulder, Colorado, is suggested in the following listing of the divisions and sectionsengaged in technical work. In general, each section carries out specialized research, development, and engineering in the field indicated by its title. A brief description of the activities, and of the resultant publications, appears on the inside of the front cover.

\section{W ASHINGTON, D. C.}

Electricity. Resistance and Reactance. Electrochemistry. Electrical Instruments. Magnetic Measurements Dielectrics. High Voltage.

Metrology. Photometry and Colorimetry. Refractometry. Photographic Research. Length. Engineering Metrology. Mass and Scale. Volumetry and Densimetry.

Heat. Temperature Physics. Heat Measurements. Cryogenic Physics. Equation of State. Statistical Physics. Radiation Physics. X-ray. Radioactivity. Radiation Theory. High Energy Radiation. Radiological Equipment. Nucleonic Instrumentation. Neutron Physics.

Analytical and Inorganic Chemistry. Pure Substances. Spectrochemistry. Solution Chemistry. StandardRefer ence Materials. Applied Analytical Research. Crystal Chemistry.

Mechanics. Sound. Pressure and Vacuum. Fluid Mechanics. Engineering Mechanics. Rheology. Combustion Controls.

Polymers. Macromolecules: Synthesis and Structure. Polymer Chemistry. Polymer Physics. Polymer Characterization. Polymer Evaluation and Testing. Applied Polymer Standards and Research. Dental Research.

Metallurgy. Engineering Metallurgy. Microscopy and Diffraction. Metal Reactions. Metal Physics. Electrolysis and Metal Deposition.

Inorganic Solids. Fngineering Ceramics. Glass. Solid State Chemistry. Crystal Growth. Physical Properties. Crystallography.

Building Research. Structural Engineering. Fire Research. Mechanical Systems. Organic Building Materials. Codes and Safety Standards. Heat Transfer. Inorganic Building Materials. Metallic Building Materials.

Applied Mathematics. Numerical Analysis. Computation. Statistical Engineering. Mathematical Physics. Operations Research.

Data Processing Systems. Components and Techniques. Computer Technology. Measurements Automation. Engineering Applications. Systems Analysis.

Atomic Physics. Spectroscopy. Infrared Spectroscopy. Far Illtraviolet Physics. Solid State Physics. Electron Physics. Atomic Physics. Plasma Spectroscopy.

Instrumentation. Engineering Electronics. Electron Devices. Electronic lnstrumentation. Mechanical Instruments. Basic lnstrumentation.

Physical Chemistry. Thermochemistry. Surface Chemistry. Organic Chemistry. Molecular Spectroscopy. Elementary Processes. Mass Spectrometry. Photochemistry and Radiation Chemistry.

Office of Weights and Measures.

\section{BOULDER, COLO.}

Cryogenic Engineering Laboratory. Cryogenic Equipment. Cryogenic Processes. Properties of Materials. Cryogenic Technical Services.

\section{CENTRAI, RADIO PROPAGATION LABORATORY}

Ionosphere Research and Propagation. Low Frequency and Very Low Frequency Research. Ionosphere Research. Prediction Services. Sun-Earth Relationships. Field Engineering. Radio Warning Services. Vertical Soundings Research.

Radio Propagation Engineering. Data Reduction Instrumentation. Radio Noise. Tropospheric Measurements. Tropospheric Analysis. Propagation-Terrain Effects. Radio-Meteorology. Lower Atmosphere Physic s.

Radio Systems. Applied Flectromagnetic Theory. High Frequency and Very High Frequency Research. Frequency Utilization. Modulation Research. Antenna Research. Radiodetermination.

Upper Atmosphere and Space Physics. Upper Atmosphere and Plasma Physics. High Latitude Ionosphere Physics. lonosphere and Exosphere Scatter. Airglow and Aurora. Ionospheric Radio Astronomy.

\section{RADIO STANDARDS LABORATORY}

Radio Physics. Radio Broadcast Service. Radio and Microwave Materials. Atonic Frequency and Time-Interval Standards. Radio Plasma. Millimeter-Wave Research.

Circuit Standards. High Frequency Electrical Standards. High Frequency Calibration Services. High Frequency Impedance Standards. Microwave Calibration Services. Microwave Circuit Standards. Low Frequency Calibration Services. 
